Article

\title{
Design and Study on Sliding Mode Extremum Seeking Control of the Chaos Embedded Particle Swarm Optimization for Maximum Power Point Tracking in Wind Power Systems
}

\author{
Jui-Ho Chen, Her-Terng Yau * and Weir Hung \\ Department of Electrical Engineering, National Chin-Yi University of Technology, Taichung 41170, \\ Taiwan; E-Mails: chenjh@ncut.edu.tw (J.-H.C.); ihhung2433@yahoo.com.tw (W.H.) \\ * Author to whom correspondence should be addressed; E-Mail: pan1012@ms52.hinet.net or \\ htyau@ncut.edu.tw; Tel.: +886-4-2392-4505 (ext. 7229); Fax: +886-4-2392-4419.
}

Received: 26 January 2014; in revised form: 23 February 2014 / Accepted: 4 March 2014 /

Published: 21 March 2014

\begin{abstract}
This paper proposes a sliding mode extremum seeking control (SMESC) of chaos embedded particle swarm optimization (CEPSO) Algorithm, applied to the design of maximum power point tracking in wind power systems. Its features are that the control parameters in SMESC are optimized by CEPSO, making it unnecessary to change the output power of different wind turbines, the designed in-repetition rate is reduced, and the system control efficiency is increased. The wind power system control is designed by simulation, in comparison with the traditional wind power control method, and the simulated dynamic response obtained by the SMESC algorithm proposed in this paper is better than the traditional hill-climbing search (HCS) and extremum seeking control (ESC) algorithms in the transient or steady states, validating the advantages and practicability of the method proposed in this paper.
\end{abstract}

Keywords: extremum seeking control (ESC); sliding mode extremum seeking control (SMESC); maximum power point tracking (MPPT); particle swarm optimization (PSO); chaos; wind power

\section{Introduction}

Due to the nonlinear characteristics of wind power generation, the output power point is usually not at the maximum power point. This paper uses maximum power point tracking (MPPT) to track the 
maximum power point so as to increase the output efficiency of the wind power [1]. There are multiple algorithms for increasing the MPPT efficiency of wind turbines, such as perturbation and observation (P\&O) [2-4], the hill-climbing search (HCS) algorithm [5,6], tip speed ratio control (TSR) [7,8], and so on. Zou et al. [9] mentioned wind power system stability analysis, using the Optimal Reference Power Curve for MPPT, and developed small signal analysis MPPT for nonlinear turbine systems.

The control of most wind power systems depends on the measurement of wind speed, and this type of system must be equipped with wind speed sensors, which are limited by the cost and complexity of the sensors [10]. Dalala et al. [11] gave experimental examples. The wind power system structure consists of an alternating current (AC) motor connected to the generator. The motor speed is controlled to simulate the onsite height and higher wind speed. This experiment is conducted for large-scale wind power systems with high output power. Bharanikumar et al. [12] and Zou et al. [13] expounded the MPPT of different turbine types of generator. Wind turbines mostly use a double fed induction generator (DFIG) [14] and permanent magnet synchronous generator (PMSG) [15]. Pan et al. [16] used MPPT simulation of DFIG wind power system parameters based on SMESC, but the SMESC given $U_{0}$ is a fixed value, not the optimized parameter, and the DFIG is controlled by multiple converters, meaning that the cost is certainly higher than PMSG, and it is also more complicated than PMSG. General control systems such as the proportion \& integration (PI) control system use the parameters $K_{\mathrm{p}}$ and $K_{\mathrm{I}}[17,18]$, which are usually fixed parameters, to control the systems. Those parameters must be obtained in accordance with the rule of thumb, so that the systems cannot get the optimal values.

In terms of the control parameter $U_{0}$ and integrated absolute error (IAE) in the SMESC proposed in this paper, the CEPSO $[19,20]$ is used to adjust the system required $U_{0}$ and IAE appropriately, to optimize the control parameters, and to validate the reliability and robustness of the control algorithm proposed in this paper. The simulation results are compared by using HCS, extremum seeking control (ESC) [21-23] and sliding mode ESC (SMESC) [24,25]. The dynamic response of the system is analyzed by the output power of the three algorithms. Chen et al. [26] used the ESC application combined with fuzzy theory to achieve maximum power point tracking. This method needs to build a set of fuzzy rules, and creates the library by rule of thumb, but also needs a longer calculation. Zazo et al. [27] proposed an effective solution called NLESC for ESC transient derivative applications of photovoltaic modules' transient response. This method explored how to make the transient response of the system more stable, reducing the vibration, and does not discuss how to eliminate the vibration of steady response. The SMESC algorithm derived from the ESC and sliding mode control (SMC) [28,29] implements wind power system MPPT simulation analysis. According to the above references, the ESC has a perfect steady-state response, and the SMCs the power to reduce the oscillation of the output waveform. In a real environment, the component lifetime loss resulting from power waveform oscillation can be reduced, so as to increase the output efficiency of the wind turbines while also reducing the cost.

The simulation system uses a rectifier to convert the AC power generated by the generator into direct current (DC) power. The controller extracts the voltage and current, and a boost circuit is used. The switching pulse width duty cycle of the conversion circuit is adjusted by the algorithm, so as to maximize the output power, exert good system performance, and increase and improve the efficiency. The SMESC not only shortens the instantaneous time, but also improves the oscillation of the output power, implementing MPPT rapidly. 


\section{Brief Introduction to Wind Power Systems}

As the real environment has different wind speed conditions, wind turbines have different power characteristic curves, so the control is required to obtain maximum power under different wind speed conditions, i.e., MPPT. As the power output of wind turbines (please refer to [30] for details of wind turbines) is related to wind speed, the power $P_{\omega \mathrm{m}}$ generated by the wind turbines can be expressed as Equation (1):

$$
P_{\omega \mathrm{m}}=\frac{1}{2} \pi \rho C_{\mathrm{p}} R^{2} V_{\omega}^{3}
$$

where $\rho$ is the air density; $R$ is the radius of blades; $V_{\omega \mathrm{m}}$ is the wind speed; and $C_{\mathrm{p}}$ is the performance coefficient of the wind turbine. $C_{\mathrm{p}}$ includes the blade tip speed ratio $\lambda$, as shown in Figure 1. $\beta$ is the pitch angle of the blades.

Figure 1. Performance coefficient curves.

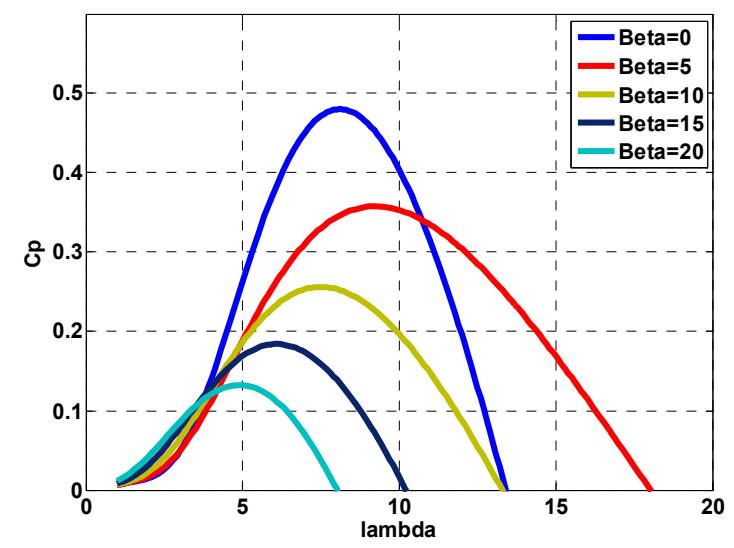

The tip speed ratio $\lambda$ is defined as the relationship between the blade tip speed and the wind speed, expressed as Equation (2):

$$
\lambda=\frac{R \omega_{\mathrm{m}}}{V_{\omega}}
$$

where $\omega_{\mathrm{m}}$ is therotational speed of the blades. Figure 2 shows the power characteristic curves at different wind speeds.

Figure 2. Power characteristic curves.

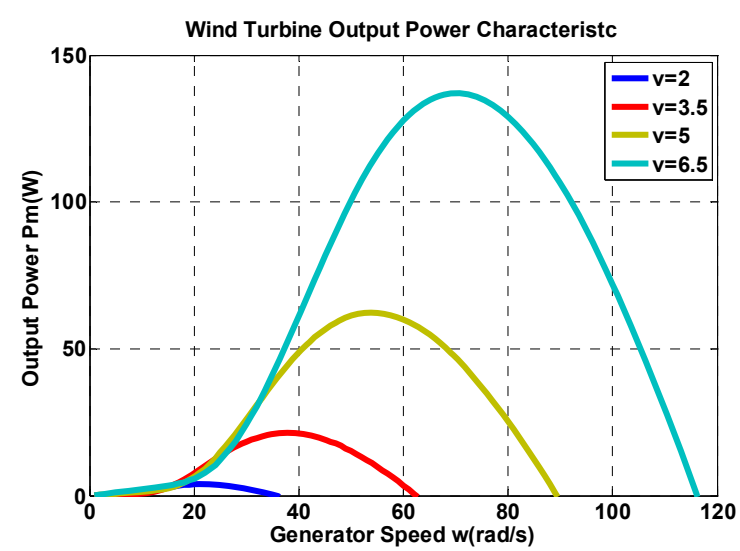


The wind power system structure proposed in this paper is shown in Figure 3. The wind turbine is coupled to the PMSG directly, connected to a rectifier, converting the AC output of the generator into DC to obtain DC voltage and current signals, and the DC is delivered to the DC-DC boost converter. The MPPT control signal is designed to control the duty cycle of switching the pulse width modulation (PWM) of the booster. Finally, the boost converter is connected to the load to measure the system output power.

Figure 3. Wind power system structure. PMSG: permanent magnet synchronous generator; DC: direct current; PWM: pulse width modulation; and MPPT: maximum power point tracking.

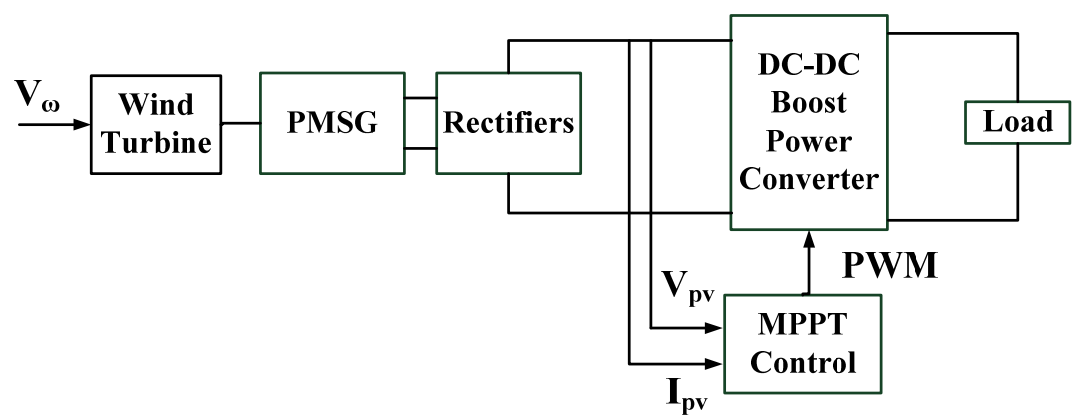

\section{Algorithms and Controller Design}

This paper uses MATLAB R2010a Simulink to build the simulated wind power system structure and to design the controller based on the output power of different algorithmic control systems. Figure 4 shows the wind power system simulation built in this paper. The module SMESC can replace different algorithms to give different switching pulse adjustment duty cycles.

Figure 4. Wind power system simulation built in this paper.

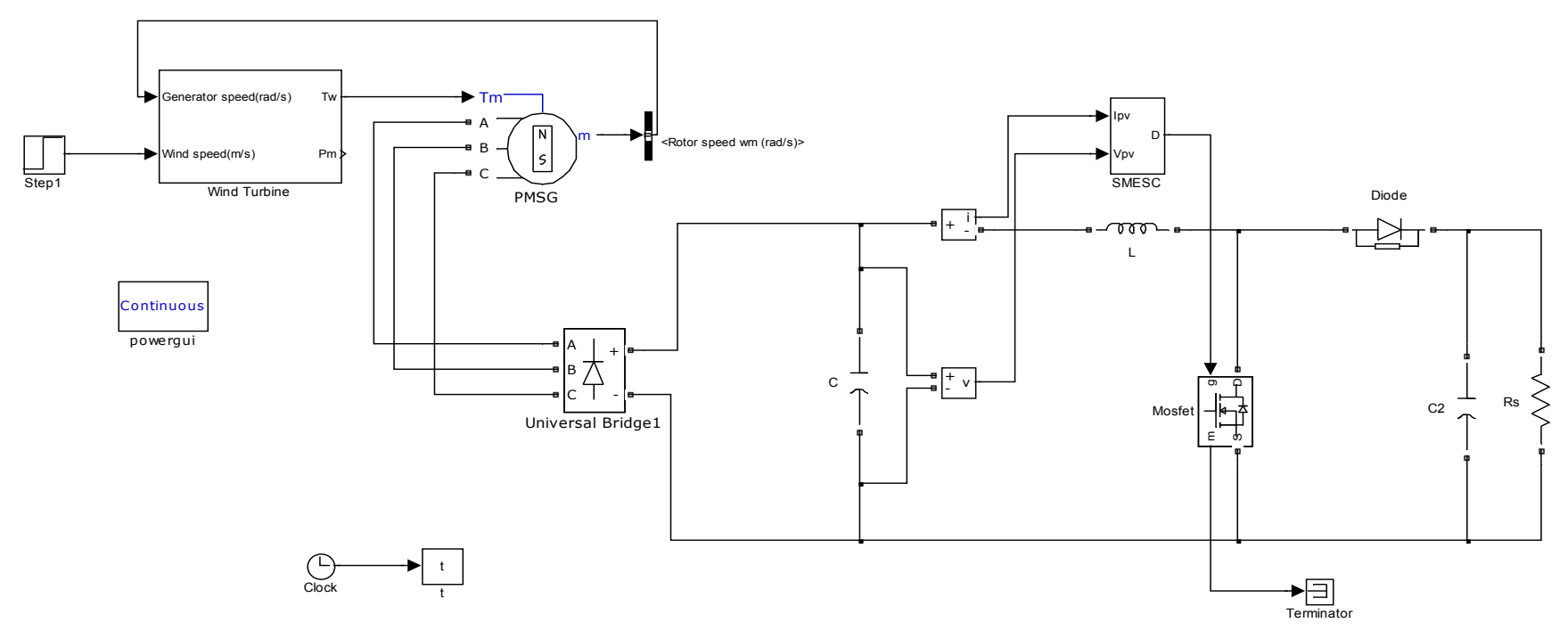

\subsection{HCS}

The most frequently used algorithm in wind power systems at variable wind speed is HCS. Assuming that the previous cycle of the wind power is $P(\omega-1)$ to produce a speed variation $\Delta \omega$, 
compare the present wind power $P(\omega)$ with $P(\omega-1)$. If the power increases, as shown in Figure 5, $\Delta \omega$ will continuously move to the optimal rotation speed; otherwise, the power decreases. Therefore, this algorithm looks for the optimum speed of the wind turbines according to the perturbation of wind speed to complete MPPT. Although it achieves better stability, the calculation time is too long, and requires setting additional wind speed sensors. An improved HCS can be derived from this algorithm (please refer to [31] for the detailed algorithm flowchart and content).

Figure 5. Curve of diagram hill-climbing search (HCS) on the characteristics of wind power.

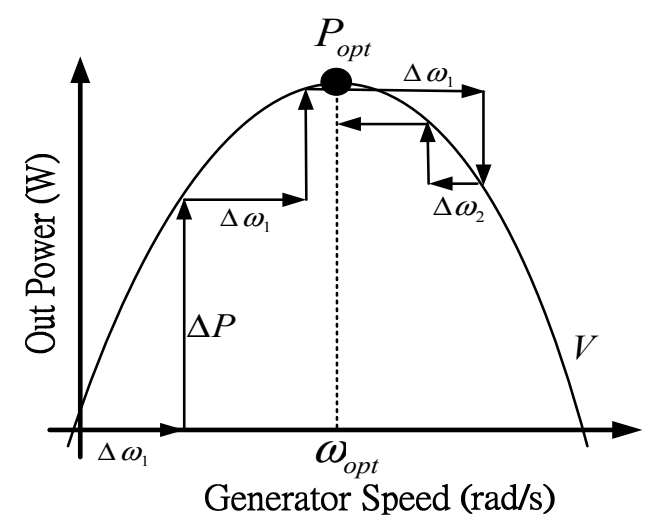

\subsection{ESC}

There have been many ESC methods proposed for solar power generation or wind power control, for which the principles are basically identical. The goal is to find the maximum value of the $X-Y$ curve in Figure 6, mainly to establish a feedback system, making the nonlinear system with slight oscillation to remain at the maximum power point, in order to achieve maximum power point tracking control. The SMESC proposed in this paper is derived from this control (please refer to [32] for detailed ESC).

Figure 6. Extremum seeking control (ESC) diagram.

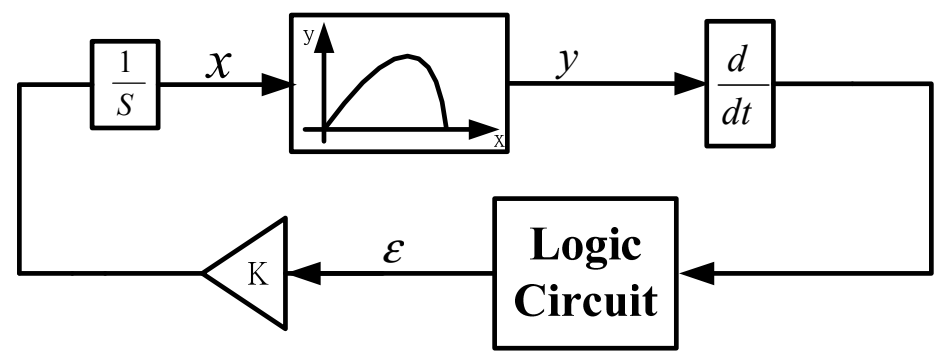

\subsection{SMESC}

In order to enhance the robustness of ESC in wind power MPPT, this paper uses the SMESC developed from the combination of SMC and ESC to further improve the output response of wind power. In conventional ESC, the switching function $\operatorname{sign}(\alpha)$ normally induce the infinite switching frequency to achieve ideal switching. The ideal frequency cannot be realized in real systems. If using an extremely high speed switching component to replace it, much high frequency noise will be created; therefore, using the concept of a sliding layer effectively inhibits the phenomenon of continuous jumping. Therefore, we use this theory to replace the $\operatorname{sign}(\alpha)$ function with the following Equation (3): 


$$
\operatorname{sat}(s, \alpha)=\left\{\begin{array}{c}
1, s>\alpha \\
\frac{s}{\alpha},|s| \leq \alpha \\
-1, s<-\alpha
\end{array}=\left\{\begin{array}{c}
\operatorname{sign}(\alpha),|s|>\alpha \\
\frac{s}{\alpha},|s| \leq \alpha
\end{array}\right.\right.
$$

Thus, the function of the following can obtain the concept of a sliding layer. As shown, Figure 7 is divided into three regions, which include $\alpha=0$ in the middle area $-\alpha<s<\alpha$, called the sliding layer, where $\alpha$ represents the thickness of the sliding layer. SMESC uses this concept of the sliding layer to replace the ESC and obtain a better inhibition effect of high frequency oscillation.

Figure 7. Concept of the sliding layer.

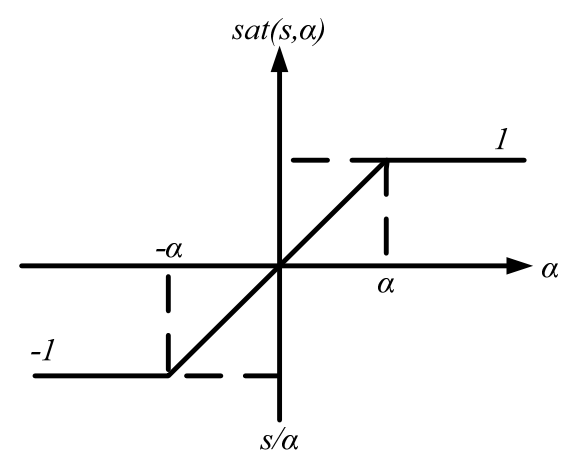

Figure 8 is the block diagram of wind power based on SMESC [33]; the control parameters in the block diagram are detailed in [34].

Figure 8. Wind power sliding mode extremum seeking control (SMESC) block diagram.

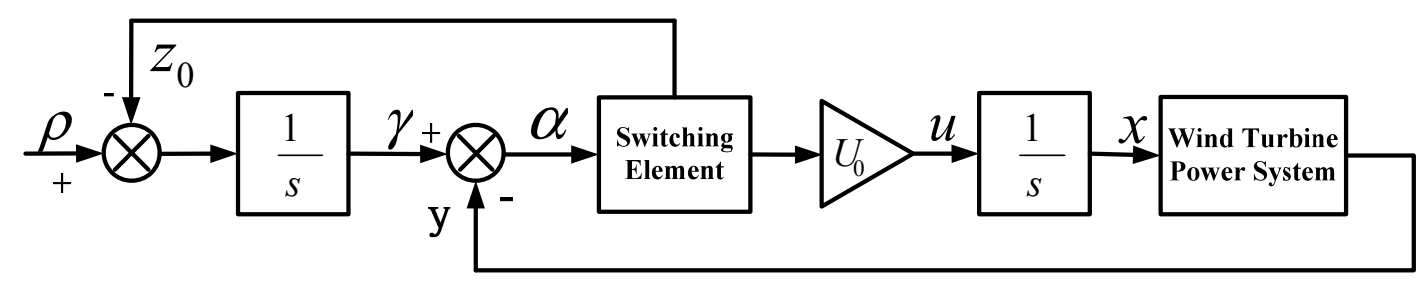

The parameters in the block diagram are expressed as Equation (4) to Equation (8):

$$
\begin{gathered}
\alpha=\gamma-y \\
u=\frac{d x}{d t} \\
u=U_{0} \cdot \operatorname{sign}(\alpha) \\
\frac{d \gamma}{d t}=\rho+Z_{0} \\
Z_{0}=-z \cdot \operatorname{sign}(\alpha)
\end{gathered}
$$

where $x$ is the wind power system input; $y$ is the wind power system output; and $z$ and $U_{0}$ are constants, expressed as Equation (4) according to Equation (9):

$$
\frac{d \alpha}{d t}=\rho-z \cdot \operatorname{sign}(\alpha)-\frac{d y}{d x} \cdot U_{0} \cdot \operatorname{sign}(\alpha)
$$

The following relationships must hold $z \gg U_{0}$ and $z \gg \rho$. 


\subsubsection{Particle Swarm Optimization (PSO)}

The PSO finds out the optimal value of particles by repeated iterations, and the most important influence is the position updating and velocity updating of particles. The velocity updating equation is expressed as Equation (10), and the position updating equation is expressed as Equation (11):

$$
\begin{gathered}
V_{i}[t+1]=V_{i}[t] \times w+c_{1} \times \text { rand } \times\left(P_{\text {best }}-X_{i}\right)+c_{2} \times \text { rand } \times\left(G_{\text {best }}-X_{i}\right) \\
X_{i}[t+1]=X_{i}[t]+V_{i}[t+1]
\end{gathered}
$$

where $V_{i}=\left[v_{i, 1}, v_{i, 2}, \ldots, v_{i, n}\right]$ is the particle velocity; $i$ is the particle number; $X_{i}=\left[x_{i, 1}, x_{i, 2}, \ldots, x_{i, n}\right]$ is the position of each particle; $w$ is the inertia weight; $c_{1}$ and $c_{2}$ are positive learning constants; rand is a random number between 0 and $1 ; P_{\text {best }}$ denotes the optimal value of each particle; and $G_{\text {best }}$ denotes the optimal value of all particles.

The computing process of PSO is shown in Figure 9, where $f_{i}$ denotes No. $i$ particle (please refer to [35] for detailed information about PSO).

Figure 9. Particle swarm optimization (PSO) flowchart.

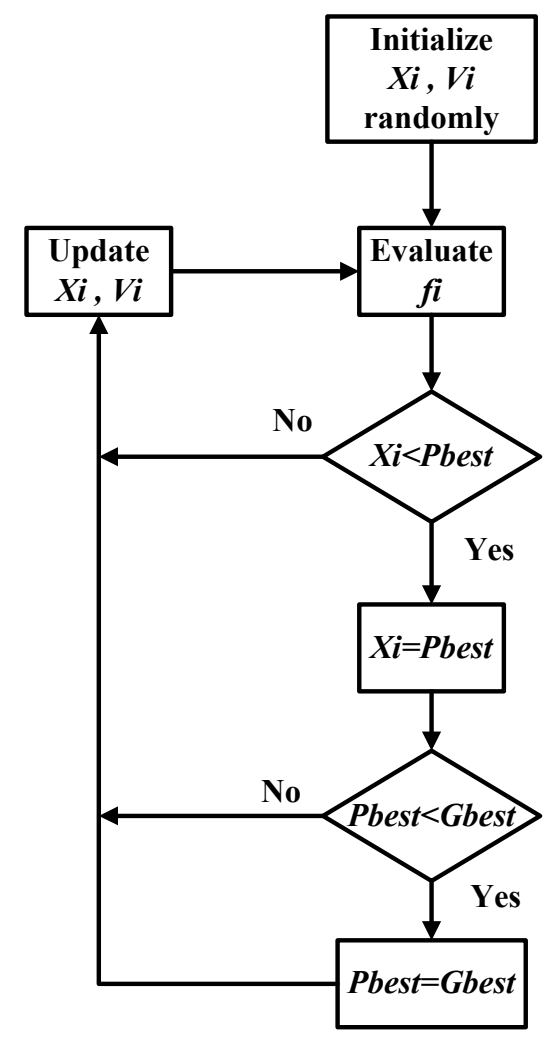

\subsubsection{Chaos Embedded Particle Swarm Optimization (CEPSO)}

As the Random function of the velocity updating equation in PSO is a random number between 0 and 1 , the value changes when the system executes programs. The varying random number results in the lowest convergence rate of seeking the optimal value. As the system complexity increases, the stability of seeking the optimal value is further influenced. The key point in the SMESC of this study is to set the control parameter $U_{0}$ and to make a goal function, IAE, defining the goal to use the algorithm to optimize the control parameter. IAE is defined as in the following Equation (12): 


$$
\mathrm{IAE}=\int_{0}^{\infty}|e(\tau)| d \tau
$$

The improved PSO and Chaos Logistic Maps are used for the two parameters, so that the control parameter obtained by the algorithm further approaches the optimal value. The Random function in velocity updating of PSO is replaced by Logistic Maps, and the errors in composing software for changing different system capacities are reduced. The new CEPSO is developed for enhancing system stability. This algorithm is detailed in [36,37].

In dynamic systems of discrete time, the Chaos Maps can be expressed as Equation(13):

$$
x_{i}=F\left(x_{i}, C\right)
$$

where $F: S \rightarrow S$ and $S \in R, S=[0,1]$ or $S=[-1,1] ; C$ is the chaos; $x$ is a vector; and $F$ is the nonlinear transfer function. The commonest Chaos Map is the Logistic Map, usually combined with PSO for application, expressed as Equation (14):

$$
x_{i+1}(k)=4 x_{i}[k]\left(1-x_{i}[k]\right)
$$

The system proposed in this paper uses the MATLAB R2010a program to compose the convergence curve, the obtained $U_{0}$ is about 0.01 , and the IAE is about the optimal value of 350 . Figures 10 and 11 show the convergence curves calculated five times, respectively.

Figure 10. $U_{0}$ convergence curves using chaos embedded particle swarm optimization (CEPSO).

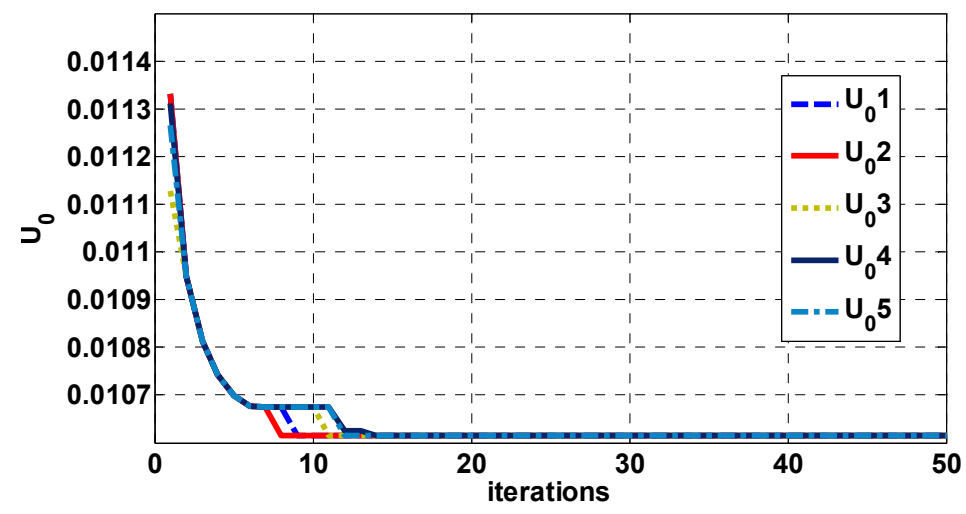

Figure 11. Integrated absolute error (IAE) convergence curves using CEPSO.

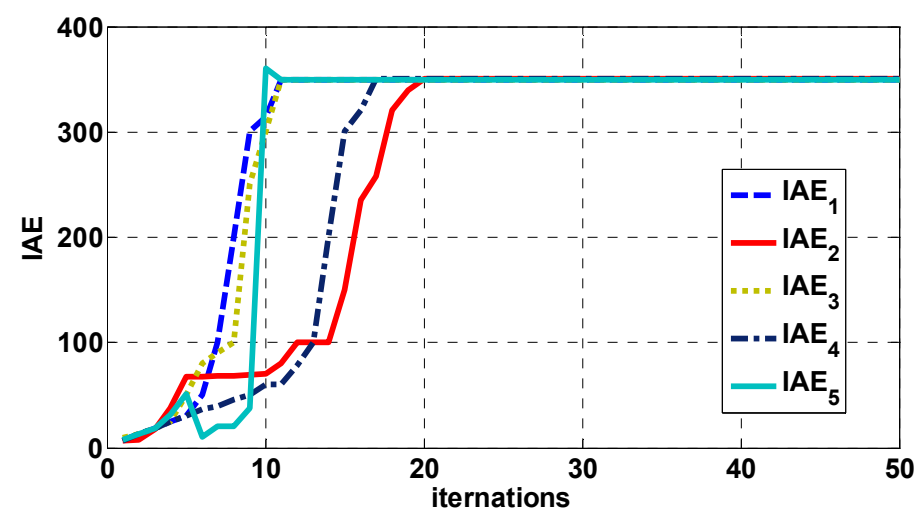




\section{MPPT Simulation Analysis Result}

According to the turbine parameters in $[38,39]$, and with the wind turbine blades pitch angle $\beta$ set as zero, the $400 \mathrm{~W}$ wind power system based on PMSG is proposed. The maximum power dynamic response of the system at constant wind speed and variable wind speed under different algorithm conditions is compared, and the merits and demerits in transient and steady-state responses are observed. Figure 12 shows the proposed maximum power point tracking flowchart. According to the simulation results, in the future wind power control development, different wind speeds can be given in real wind turbine control experiments to test the output dynamic response of real wind turbines, so as to validate the practicability of the SMESC algorithm used in this paper for the wind energy industry.

Figure 12. Proposal based on SMESC of CEPSO for the MPPT flowchart.

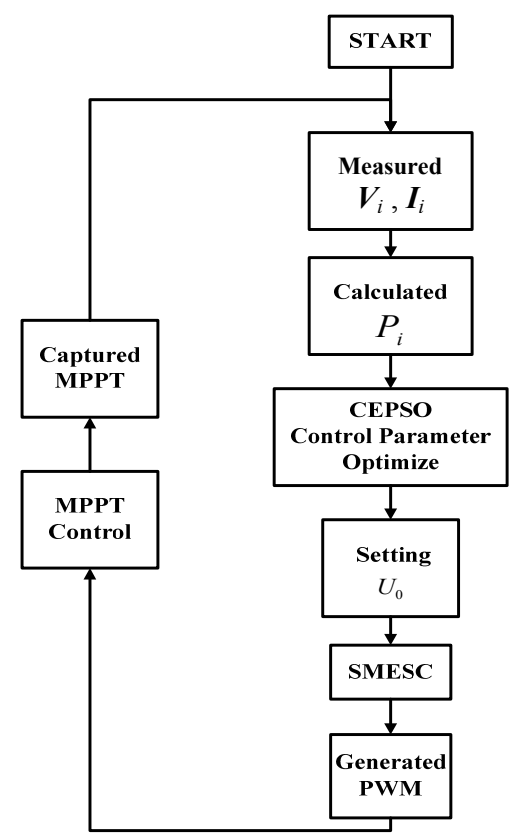

This paper simulates two wind speed input conditions. Figure 13 shows the constant wind speed condition of $12.5 \mathrm{~m} / \mathrm{s}$, while the other wind speed condition is shown in Figure 14. The wind speed of $12.5 \mathrm{~m} / \mathrm{s}$ is reduced to $10.5 \mathrm{~m} / \mathrm{s}$ in about $10 \mathrm{~s}$, and then is returned to $12.5 \mathrm{~m} / \mathrm{s}$, so as to observe the MPPT of the wind power system under variable wind speed conditions within $50 \mathrm{~s}$.

Figure 13. Step input constant wind speed $12 \mathrm{~m} / \mathrm{s}$.

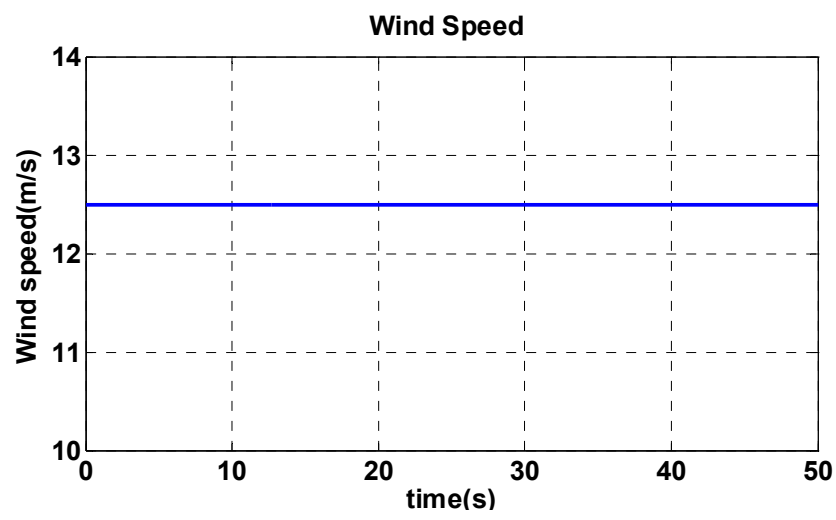


Figure 14. Changes within step input variable wind speed of $10.5-12.5 \mathrm{~m} / \mathrm{s}$.

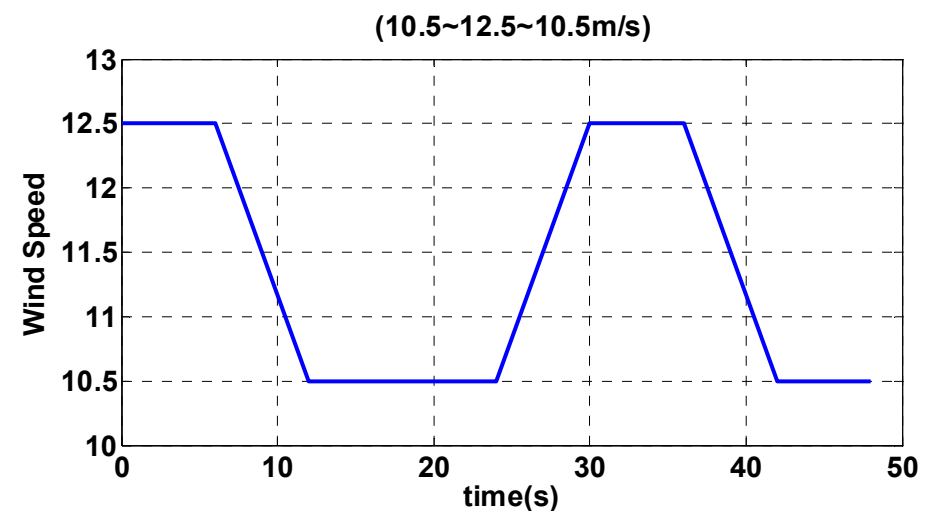

As shown in Figure 15, it is observed in the transient state that the tracking time of ESC is longer than the other two control methods, the dynamic response of HCS is similar to SMESC, but the response in the steady state is worse than the SMESC used in this paper.

Figure 15. Output dynamic response of HCS, ESC and SMESC algorithms, respectively (constant wind speed).

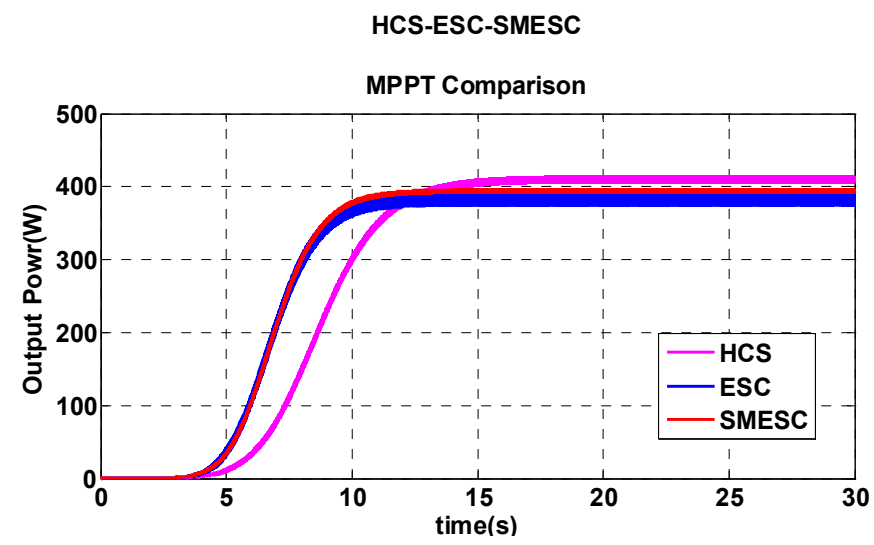

It is observed in Figure 16 that the oscillation amplitude of SMESC is better than the other two control methods. Therefore, the simulation result of this paper proves that the SMESC algorithm used in this paper has good dynamic response under constant wind speed conditions.

Figure 16. Output dynamic response of HCS, ESC and SMESC algorithms, respectively (constant wind speed) (24-24.5 s).

HCS-ESC-SMESC

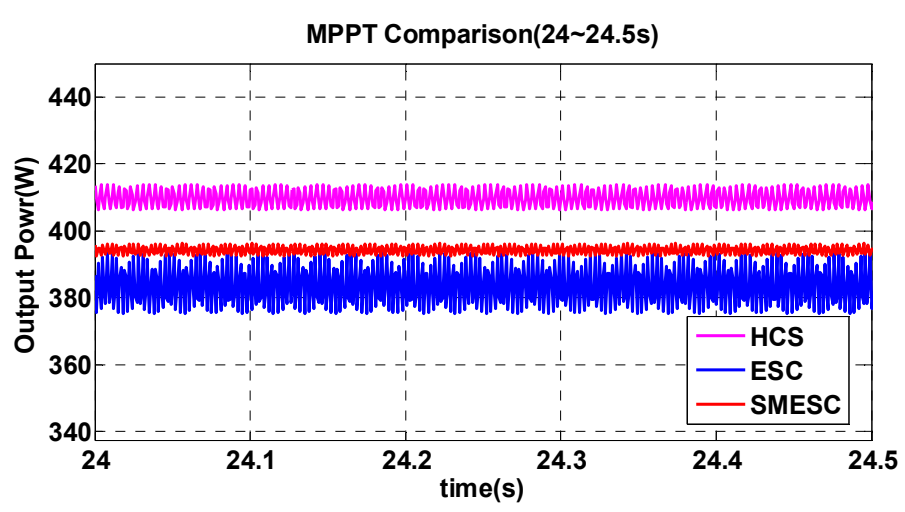


The second simulated condition is to test the system output dynamic response of the SMESC algorithm used in this paper under variable wind speed conditions. Figure 14 shows the step input variable wind speed condition. So that the wind speed is similar to the input of the square-wave pattern, it changes between $10.5 \mathrm{~m} / \mathrm{s}$ and $12.5 \mathrm{~m} / \mathrm{s}$.

According to the system simulation result in Figure 17, it is more obvious that although the amplitude of general ESC at variable wind speed is small, as shown in Figures 18 and 19, the MPPT has more harmonics. Then the HCS tracks the maximum power point slowly, and the amplitude is larger than SMESC. This simulation proves that the SMESC has better transient and steady-state responses in the wind power systems at variable wind speed conditions. It contributes not only to extending the component lifetime, but also to shortening the simulation time. According to the simulation results, in the future real machine experiment, this algorithm can be applied to wind power systems, to help the system perform more efficiently, and this application result can be used better, further developing the renewable energy industry.

Figure 17. Output dynamic response of HCS, ESC and SMESC algorithms, respectively (variable wind speed, $10.5-12.5 \mathrm{~m} / \mathrm{s}$ ).

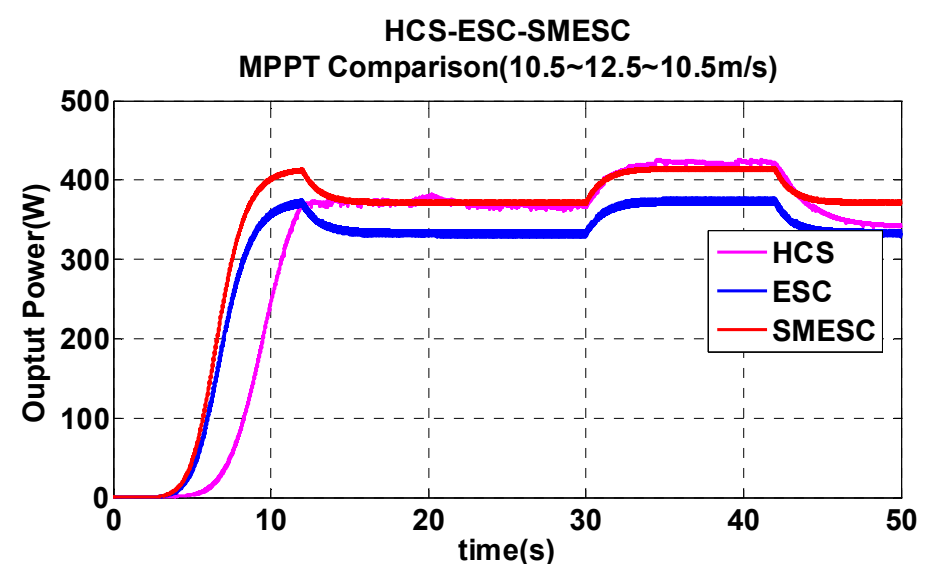

Figure 18. Output dynamic response of HCS, ESC and SMESC algorithms, respectively (variable wind speed, $10.5-12.5 \mathrm{~m} / \mathrm{s})(20-21 \mathrm{~s}$ ).

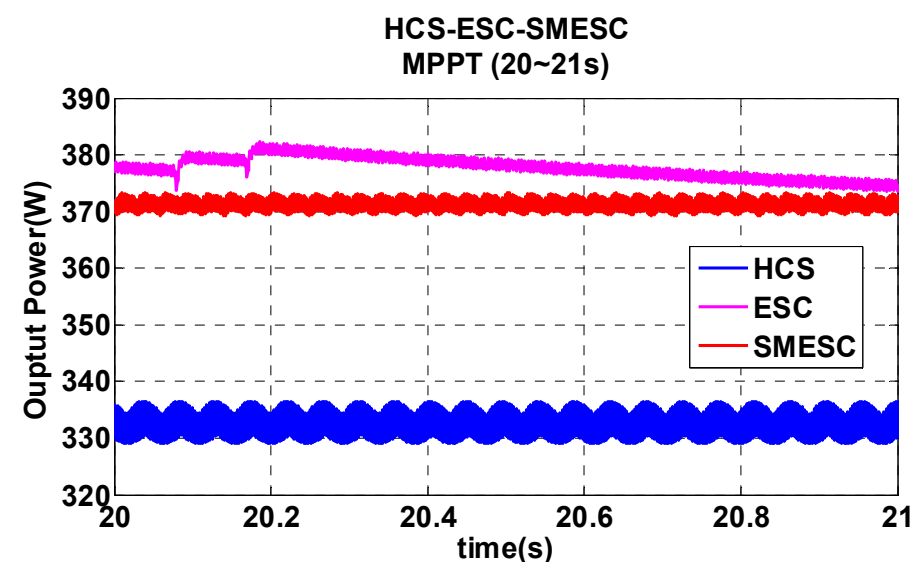


Figure 19. Output dynamic response of HCS, ESC and SMESC algorithms respectively (variable wind speed, $10.5-12.5 \mathrm{~m} / \mathrm{s})(34-36 \mathrm{~s})$.

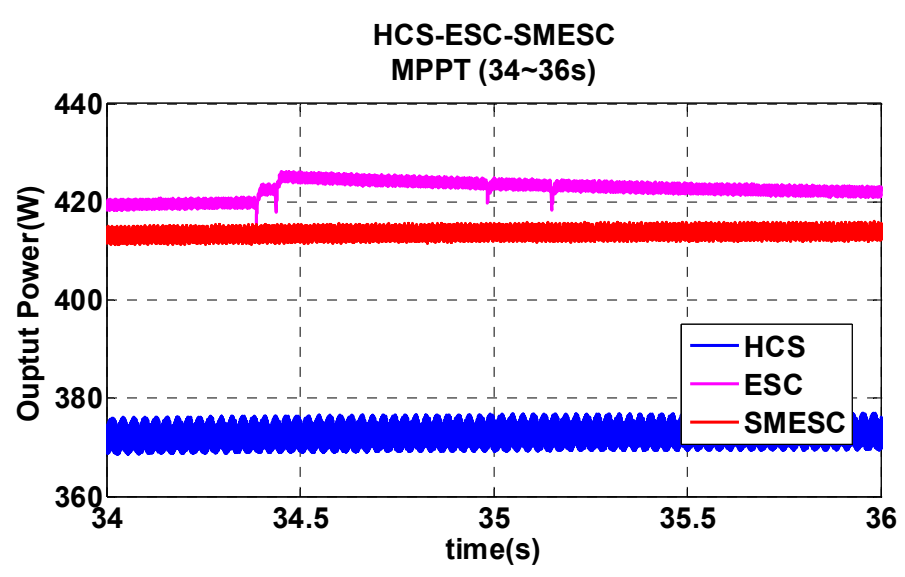

\section{Conclusions}

This study used the SMESC of CEPSO for wind power system control. It is unnecessary to adjust the control parameter according to different control system output powers, not only to optimize the control parameter in SMESC, but also to reduce the designed in-repetition. According to the simulation results of the algorithm, the control response of the system is stable compared with other methods, it prolongs the component lifetime effectively, and the transient response and steady-state response of SMESC are better than those of ESC and HCS, making the system implement MPPT faster to reach the required output power. It can also be applied to real machine system experiments in the future.

\section{Conflicts of Interest}

The authors declare no conflict of interest.

\section{References}

1. Kortabaria, I.; Andreu, J.; deAlegria, I.M.; Ibara, E.; Robles, E. Maximum Power Extraction Algorithm for Small Wind Turbine. In Proceedings of the 14th International Power Electronics and Motion Control Conference (EPE/PEMC), Ohrid, Macedonia, 6-8 September 2010; pp. T12:49-T12:54.

2. Fernia, N.; Perurone, G.; Spagnuolo, G.; Vitelli, M. Optimizing Duty-Cycle Perturbation of P\&O MPPT Technique. In Proceedings of the IEEE 35th Annual Power Electronics Specialists Conference (PESC), Aachen, Germany, 20-25 June 2004; Volume 3, pp. 1939-1944.

3. Mahdi, A.J.; Tang, W.H.; Wu, Q.H. Estimation of Tip Speed Ratio Using an Adaptive Perturbation and Observation Method for Wind Turbine Generator Systems. In Proceedings of the IET Conference on Renewable Power Generation (RPG), Edinburgh, UK, 6-8 September 2011; pp. 1-6.

4. Mahdi, A.J.; Tang, W.H.; Wu, Q.H. Novel Perturbation and Observation Algoritms for Variable-Speed Wind Turbine Generator Systems. In Proceedings of the IEEE Power and Energy Society General Meeting, San Diego, CA, USA, 22-26 July 2012; pp. 1-8. 
5. RazaKazmi, S.M.; Goto, H.; Wu, Q.H. A novel algoritm for fast and efficient speed-sensorless maximum power point tracking in wind energy conversion systems. IEEE Trans. Ind. Electron. 2011, 58, 29-36.

6. Yamakura, S.;Kesmaru, K. Dynamic Simulation of PMSG Small Wind Turbine Generation System with HCS-MPPT Control. In Proceedings of the 15th International Conference on Electrical Machines and Systems (ICEMS), Sapporo, Japan, 21-24 October 2012; pp. 1-4.

7. Tatsuta, F.; Suzuki, K.; Nishikata, S. A New Control Method to Realize Constant Tip Speed Ratio of Series Connected Wind Turbine Generators. In Proceedings of the International Conference on Clean Electrical Power (ICCEP), Alghero, Italy, 11-13 June 2013; pp. 434-439.

8. Yokoyama, H.; Tatsuta, F.; Nishikata, S. Tip Speed Ratio Control of Wind Turbine Generating System Connected in Series. In Proceedings of the International Conference on Electrical Machines and Systems (ICEMS), Beijing, China, 20-23 August 2011; pp. 1-4.

9. Zou, Y.; Elbuluk, M.; Sozer, Y. Stability Analysis of Maximum Power Point Tracking (MPPT) Method in Wind Power Systems. In Proceedings of the IEEE Industry Applications Society Annual Meeting (IAS), Orlando, FL, USA, 9-13 October 2011; pp. 1-8.

10. Koutroulis, E.; Kalatizakis, K. Design of a Maximum Power Point Tracking System for Wind-Energy-Conversion Applications. IEEE Trans. Ind. Electron. 2006, 53, 486-489.

11. Dalala, Z.M.; Zahid, Z.U.; Yu, W.S.; Cho, Y.H.; Lai, J.S. Design and analysis of an MPPT technique for small-scale wind energy conversion systems. IEEE Trans. Energy Convers. 2013, 28, 756-767.

12. Bharanikumar, R.; Yazhini, A.C.; Nirmal Kumar, A. Novel Maximum Power Point Tracking Controller for Wind Turbine Driven Permanent Magnet Generator. In Proceedings of the Joint International Conference on Power System Technology and IEEE Power India Conference, New Delhi, India, 12-15 October 2008; pp. 1-6.

13. Zou, Y.; Elbuluk, M.; Sozer, Y. A Novel Maximum Power Points Tracking (MPPT) Operation of Doubly-Fed Induction Generator (DFIG) Wind Power Systems. In Proceedings of the IEEE Industry Applications Society Annual Meeting (IAS), Las Vegas, NV, USA, 7-11 October 2012; pp. 1-6.

14. Chitti Babu, B.; Mohanty, K.B. Doubly-Fed Induction Generator for Variable Speed Wind Energy Conversion Systems-Modeling \& Simulation. Int. J. Comput. Electr. Eng. 2010, 2, 141-147.

15. Yang, X.; Gong, X. Mechanical Sensorless Maximum Power Point Tracking Control for Direct-Driven PMSG Wind Turbine. In Proceedings of the IEEE Energy Conversion Congress and Exposition (ECCE), Atlanta, GA, USA, 12-16 September 2010; pp. 4091-4098.

16. Pan, T.L.; Ji, Z.C.; Jiang, Z.H. Maximum Power Point Tracking of Wind Energy Conversion Systems Based on Sliding Mode Extremum Seeking Control. In Proceedings of the IEEE Energy 2030 Conference, Atlanta, GA, USA, 17-18 November 2008; pp. 1-5.

17. Uma, S.P.; Manikandan, S. Control Technique for Variable Speed Wind Turbine using PI Controller. In Proceedings of the International Conference on Emerging Trends in Computing, Communication and Nanotechnology (ICE-CCN), Tirunelveli, India, 25-26 March 2013; pp. 640-643.

18. Torres-Salomao, L.A.; Gamez-Cuatzin, H. Fuzzy Logic Control and PI Control Comparison for a 1.5 MW Horizontal Axis Wind Turbine. In Proceedings of the 16th International Conference on System Theory, Control and Computing (ICSTCC), Sinaia, Romania, 12-14 October 2012; pp. 1-6. 
19. Altinoz, O.T.; Yilmaz, A.E.; Weber, G.-W. Application of Chaos Embedded PSO for PID Parameter Tunning. Int. J. Comput. Commun. 2012, 7, 204-217.

20. Eberhart, R.; Kennedy, J. A New Optimizer Using Particle Swarm Theory. In Proceedings of the Sixth International Symposium on Micro Machine and Human Science, Nagoya, Japan, 4-6 October 1995; pp. 39-43.

21. Olalla, C.; Arteaga, M.I.; Leyva, R.; EI Aroudi, A. Analysis and Comparison of Extremum Seeking Control Techniques. In Proceedings of the IEEE International Symposium on Industrial Electronics, Vigo, Spain, 4-7 June 2007; pp. 72-76.

22. Bratcu, A.I.; Munteanu, I.; Ceanga, E.; Epure, S. Energetic Optimization of Variable Speed Wind Energy Conversion Systems by Extremum Seeking Control. In Proceedings of the International Conference on "Computer as a Tool", EUROCON, Warsaw, Poland, 9-12 September 2007; pp. 2536-2541.

23. Ghaffari, A.; Krstic, M.; Seshagiri, S. Power Optimization and Control in Wind Energy Conversion Systems using Extremum Seeking. In Proceedings of the American Control Conference (ACC), Washington, DC, USA, 17-19 June 2013; pp. 2241-2246.

24. Pan, Y.D.; Ozguner, U. Extremum Seeking Control with Sliding Mode. In Proceedings of the IFAC 15th Triennial World Congress, Barcelona, Spain, 21-26 July 2002.

25. Fu, L. Model-Based Extremum Seeking Control for a Class of Nonlinear Systems. Ph.D. Thesis, Ohio State Univeristy, Columbus, OH, USA, July 2010.

26. Chen, Q.; Wang, S.H.; Wang, L.G. Wind Power Generation System Using Fuzzy Extreme Seeking Control. In Proceedings of the 31st Chinese Control Conference, Hefei, Anhui, China, 25-27 July 2012; pp. 3545-3547.

27. Zazo, H.; del Castillo, E.; Reynau, J.F.; Leyva, R. MPPT for Photovoltaic Modules via Newton-Like Extremum Seeking Control. Energies 2012, 5, 2652-2666.

28. Boulaam, K.; Boukhelifa, A. Maximum Power Point Tracking Based on Sliding Mode Control. In Proceedings of the International Aegean Conference on Electrical Machines and Power Electronics and Electromotion Joint Conference (ACEMP), Istanbul, Turkey, 8-10 September 2011; pp. 59-63.

29. Sabanovic, A.; Fidman, L.M.; Spurgeon, S.K. Variable Structure Systems: From Principles to Implementation; Instiution of Engineering and Technology: London, UK, 2004; pp. 3-17.

30. Behnke, M.; Ellis, A.; Kazachkov, Y.; McCoy, T.; Muljadi, E.; Price, W.; Sanchez-Gasca, J. Development and Validation of WECC Variable Speed Wind Turbine Dynamic Models for Grid Integration Studies. In Proceedings of the AWEA's WindPower Conference, Los Angeles, CA, USA, 4-7 June 2007.

31. Gao, J.; Lu, J.; Huang, K.; Zhang, Y.; Huang, S. A Novel Variable Step Hill-Climb Search Algorithm Used for Direct Driven PMSG. In Proceedings of the International Conference Energy and Environment Technology, Guilin, Guangxi, China, 16-18 October 2009; pp. 511-514.

32. Krstic, M.; Wang, H.H. Design and Stability Analysis of Extremum Seeking Feedback for General Nonlinear Systems. In Proceedings of the 36th IEEE Conference on Decision and Control, San Diego, CA, USA, 10-12 December 1997; Volume 2, pp. 1743-1748. 
33. Ciampichetti, S.; Corradini, M.L.; Ippoliti, G.; Orlando, G. Sliding Mode Control of Permanent Magnet Synchronous Generator for Wind Turbines. In Proceedings of the 37th Annual Conference on IEEE Industrial Electronics Society, Melbourne, Australia, 7-10 November 2011; pp. 740-745.

34. Yau, H.T.; Lin, C.J.; Wu, C.H. Sliding mode extremum seeking control scheme based on PSO for maximum power point tracking in photovoltaic systems. Int. J. Photoenergy 2013, 2013, doi:10.1155/2013/527948.

35. Korovin, S.K.; Utkin, V.I. Using sliding mode in static optimization and nonlinear programming. Automatica 1974, 10, 525-532.

36. Liu, B.; Wang, L.; Jin, Y.-H.; Tang, F.; Huang, D.-X. Improved particle swarm optimization combined with chaos. Chaos Solitons Fractals 2005, 25, 1261-1271.

37. Pluhacek, M.; Senkerik, R.; Zelinka, I.; Davendra, D. Chaos PSO Algorithm Driven Alternately by Two Different Chaotic Maps-An Initial Study. In Proceedings of the IEEE Congress on Evolutionary Computation, Cancun, Mexico, 20-23 June 2013; pp. 2444-2449.

38. Li, Z.M.; Sun, Q.Z.; Sun, Y.; Han, X.P. Maximum energy tracking of pmsg wind power generation system by fractional-order control. Proc. Chin. Soc. Univ. Electr. Power Syst. Autom. 2012, 24, 67-72.

39. Liao, Y.-C. Design and Implementation of Power Converters for Wind Generator. Master's Thesis, National Yunlin University of Science and Technology, Yunlin, Taiwan, July 2008.

(C) 2014 by the authors; licensee MDPI, Basel, Switzerland. This article is an open access article distributed under the terms and conditions of the Creative Commons Attribution license (http://creativecommons.org/licenses/by/3.0/). 